\title{
Razões da Fragmentação: Coligações e Estratégias Partidárias na Presença de Eleições Majoritárias e Proporcionais Simultâneas ${ }^{*}$
}

\author{
André Borges ${ }^{1}$ \\ ${ }^{1}$ Professor Adjunto do Instituto de Ciência Política (IPOL) da Universidade de Brasília (UnB). Brasília, DF. \\ Brasil, Pesquisador visitante, CILAS - University of California, San Diego, CA. EUA. \\ E-mail: andrebor75@gmail.com, https:// orcid.org/0000-0002-2129-8091
}

\begin{abstract}
A s explicações institucionalistas sobre o formato dos sistemas A partidários asseguram que eleições presidenciais e congressuais simultâneas, na presença de pequeno número de candidatos à presidência eleitoralmente relevantes, reduzem o número de candidatos viáveis na disputa ao Legislativo. O efeito redutor da eleição presidencial resultaria da associação entre a sorte eleitoral dos candidatos mais competitivos à presidência e de seus copartidários na disputa à Câmara, por meio do chamado "efeito rabo de casaca" (coattail effect). Por essa lógica, partidos sem candidatos viáveis à presidência tenderiam a perder votos, sendo o oposto verdadeiro para os primeiros colocados no pleito presidencial (Samuels, 2002; Golder, 2006; Hicken e Stoll, 2011).
\end{abstract}

Em face dessa literatura, o caso brasileiro apresenta um paradoxo. A mudança de um regime eleitoral caracterizado por eleições legislativas majoritariamente não coincidentes com a eleição presidencial (1945-1964), para um regime de simultaneidade plena entre os pleitos, a partir de 1994, não implicou nenhuma melhora significativa na coordenação eleitoral entre as arenas presidencial e legislativa. Pelo contrário, em que pese a estabilização do número efetivo de candidatos presidenciais entre dois e três no período recente, o número de

\footnotetext{
*A pesquisa se beneficiou do apoio financeiro concedido pela Fundação de Apoio à Pesquisa do Distrito Federal (FAPDF), por meio dos editais 05/2013 e 03/2015 (processos 0193.000891/2015 e 193.000.215/2014), ao longo dos anos de 2017 e 2018. Agradeço também aos pareceristas anônimos da revista DADOS a leitura cuidadosa e as críticas certeiras que muito contribuíram para o aperfeiçoamento das análises e dos argumentos na primeira versão do manuscrito.
}

DADOS, Rio de Janeiro, vol.62(3):e20170223, 2019. 
partidos na disputa legislativa nacional cresceu de forma acelerada ao longo dos anos 1990 e 2000. Em 2014, o número efetivo de partidos eleitorais no pleito para a Câmara dos Deputados chegou a 14, número sem paralelo no mundo ${ }^{1}$.

Do ponto de vista teórico, a consolidação da disputa presidencial em torno de dois partidos - Partido dos Trabalhadores (PT) e Partido da Social Democracia Brasileira (PSDB) - deveria ser transferida, paulatinamente, para a disputa nacional proporcional simultânea. Apresenta-se, assim, a questão de entender por que o efeito rabo de casaca não produziu os efeitos esperados no caso brasileiro, levando ao predomínio dos principais partidos presidenciais nas eleições para a Câmara dos Deputados.

Segundo uma interpretação influente sobre a elevada fragmentação partidária no Brasil, a combinação entre distritos de grande magnitude, voto preferencial e quase ausência de barreiras à criação de novos partidos favorece a competição intrapartidária e as estratégias individualistas de campanha, levando a um cenário de virtual atomismo partidário (Mainwaring, 1999; Ames, 2001). Nesse sentido, não caberia esperar uma associação significativa entre as votações dos partidos nos pleitos para o Executivo e o Legislativo em razão do efeito mecânico do sistema eleitoral proporcional utilizado para eleger os deputados federais, em contraponto à regra majoritária na disputa presidencial (Zucco, 2008; Limongi e Cortez, 2010). Todavia, conforme demonstrado por Hicken e Stoll (2011), o efeito redutor da eleição presidencial sobre o número de partidos competindo em cada distrito deverá ser tão mais intenso quanto mais proporcional for o sistema eleitoral utilizado para eleger os parlamentares. Desse ponto de vista, as evidências contrariam totalmente o suposto de que o efeito rabo de casaca seria mais fraco em sistemas políticos com alta magnitude de distrito; em realidade, o que se observa é a relação inversa.

Alguns estudos recentes argumentam que, no caso brasileiro, os partidos se beneficiam do efeito rabo de casaca tanto em função da participação na eleição presidencial quanto na eleição para governador (Soares, 2013; Borges, 2015). Tais pesquisas, porém, não se preocupam em entender, mais especificamente, se e de que forma a realização de eleições simultâneas para governador e presidente reduz a vinculação entre o desempenho dos partidos nessa última disputa $\mathrm{e}$ nas eleições para deputado federal. 
Tornou-se influente, na ciência política brasileira, o diagnóstico de que os impactos da fragmentação partidária sobre a formação e a operação das coalizões governamentais são minimizados em nosso sistema político, uma vez que os extensivos poderes legislativos do presidente, em conjunção com a organização centralizada do Congresso, permitem que o chefe do Executivo e os líderes partidários da coalizão exerçam grande controle sobre o processo legislativo (Figueiredo e Limongi, $1999,2000)$. Contudo, essas análises ignoram o fato de que o multipartidarismo extremo se associa a gabinetes mais instáveis e menos duradouros (Martínez-Gallardo, 2010, 2012). A fragmentação partidária também está associada à maior dispersão ideológica, o que, por sua vez, aumenta substancialmente os custos de montagem e de administração das coalizões (Amorim Neto, 2007; Pereira et al., 2016).

Neste artigo, o objetivo é explicar a dissociação entre as eleições presidenciais e a estrutura da competição partidária no pleito para deputado federal no Brasil em função da dinâmica de formação de coligações em torno dos principais candidatos à presidência. Para a literatura sobre o efeito rabo de casaca, apenas os partidos capazes de lançar candidato próprio à presidência obteriam benefícios eleitorais da entrada na disputa presidencial. No entanto, é argumentado aqui que (H1) a formação de coligações multipartidárias resulta em um efeito rabo de casaca difuso (diffused coattail effect), uma vez que não apenas os partidos capazes de lançar candidatos mas também seus aliados se beneficiam do sucesso eleitoral na disputa à presidência (Borges e Turgeon, 2019). Isso ocorre porque os partidos com candidato próprio à presidência necessitam fazer concessões para obter o apoio de outros partidos; por exemplo, abrindo mão de lançar candidatos, formando coligações em outras disputas simultâneas ou evitando concorrer com os aliados em seus redutos eleitorais.

No caso brasileiro, a estrutura federativa, em combinação com as regras eleitorais, faz com que as eleições para o Executivo estadual tenham grande impacto sobre a estrutura da competição para a Câmara dos Deputados nos distritos. Assim, a troca de apoios entre disputas, necessária para viabilizar a formação de coligações multipartidárias no pleito presidencial, tem como um de seus eixos a barganha em torno das eleições para governador. A coordenação intracoligação acaba por favorecer os partidos coligados nas disputas a governador e a deputado federal, ao mesmo tempo que reduz os ganhos eleitorais dos cabeças de chapa. Em suma, (H2) a entrada nas eleições de 
governador apoiando outras legendas reduz os ganhos esperados de entrada na eleição presidencial com candidato próprio.

A fim de testar essas hipóteses, neste artigo é desenvolvida uma série de modelos estatísticos para estimar a votação nacional dos partidos em todas as disputas para a Câmara dos Deputados entre 1994 e 2014 como função das estratégias de entrada nas disputas para governador e presidente. Os resultados das análises demonstram que os ganhos eleitorais da entrada na disputa presidencial se reduzem quanto maior é a frequência de apoios concedidos a outras legendas no pleito para governador. Além disso, os partidos coligados obtêm ganhos eleitorais participando da disputa presidencial. No entanto, esse efeito só se verifica para os partidos de oposição; para as legendas que já fazem parte da coalizão governista, entrar em uma coligação na disputa presidencial não produz ganhos relevantes. Conclui-se que a fragmentação partidária é parcialmente endógena ao sistema coalizacional do presidencialismo brasileiro, uma vez que a formação de amplas coalizões pré- e pós-eleitorais favorece a sobrevivência e o crescimento eleitoral das pequenas legendas.

\section{ELEIÇÕES PRESIDENCIAIS E LEGISLATIVAS SIMULTÂNEAS E SEUS IMPACTOS SOBRE A COORDENAÇÃO ELEITORAL}

O impacto da eleição presidencial sobre o sistema partidário depende, em boa medida, da força do chamado "efeito coattails" (efeito rabo de casaca), pelo qual o presidente atua como um "puxador de votos", beneficiando os candidatos de seu partido/coalizão ao Legislativo. Dois aspectos explicam a ocorrência do efeito coattails nos sistemas presidenciais: em primeiro lugar, o Executivo nacional é o principal "prêmio eleitoral" no presidencialismo. Com isso, os candidatos ao Legislativo contam com consideráveis incentivos para vincular sua campanha à campanha presidencial com o intuito de se beneficiar das vantagens organizacionais, financeiras e da cobertura de mídia de seu candidato à presidência (Samuels, 2002). O segundo ponto é que os eleitores também reconhecem a centralidade e a importância das eleições presidenciais e, muitas vezes, utilizam-se do partido de seu candidato presidencial preferido com um atalho informacional para ajudá-los a decidir o voto na eleição legislativa (Shugart, 1995; Samuels, 2002; Golder, 2006). As evidências reunidas em várias pesquisas indicam ainda que o efeito coattails será tanto mais significativo quanto maior a proximidade temporal entre as eleições presi- 
denciais e as eleições legislativas (Shugart e Carey, 1992; Jones, 1994; Golder, 2006; Hicken e Stoll, 2011).

Do ponto de vista analítico, pode-se dizer que o efeito rabo de casaca engloba efeitos que operam no nível do eleitor individual - eleições presidenciais como atalho informacional - e efeitos relativos aos processos de coordenação estratégica envolvendo partidos e candidatos. No que diz respeito a essa segunda dimensão, denominada aqui de coordenação horizontal, partidos que contam com um candidato competitivo à presidência devem lançar mais candidatos na disputa legislativa simultânea do que lançariam se estivessem ausentes da disputa ao Executivo nacional, na expectativa de se beneficiar de ganhos de escala financeiros, logísticos e de mídia da candidatura presidencial. A lógica inversa se verificaria para os partidos sem candidatos presidenciais viáveis: seria de se esperar que lançassem um número menor de candidatos - ou mesmo a migração de parte de seus candidatos para as legendas competitivas.

Dada a vinculação entre o desempenho eleitoral dos partidos na eleição majoritária (presidencial) e na eleição proporcional (legislativa), um número suficientemente baixo de candidatos eleitoralmente viáveis na disputa à presidência deve resultar na redução do tamanho do sistema partidário, além de promover sua nacionalização (Cox, 1999; Hicken e Stoll, 2011). O Quadro 1 exemplifica os efeitos esperados da eleição presidencial sobre a coordenação eleitoral na eleição para o Legislativo nacional, supondo um número pequeno de candidatos competitivos à presidência.

Quadro 1

Coordenação Eleitoral na Presença de Eleições Presidenciais e Legislativas Coincidentes, sem Coligações

\begin{tabular}{|c|c|c|c|}
\hline & Distrito 1 & Distrito 2 & Distrito 3 \\
\hline Partidos na corrida presidencial & $\mathrm{A}, \mathrm{B}, \mathrm{C}$ & $\mathrm{A}, \mathrm{B}, \mathrm{C}$ & $\mathrm{A}, \mathrm{B}, \mathrm{C}$ \\
\hline $\begin{array}{l}\text { Partidos com votação acumulada }>=80 \% \\
\text { na corrida presidencial }\end{array}$ & $A, B$ & A, B & A, B \\
\hline $\begin{array}{l}\text { Partidos competindo na eleição para } \\
\text { deputado federal }\end{array}$ & $\mathrm{A}, \mathrm{B}, \mathrm{C}, \mathrm{D}, \mathrm{M}$ & $\mathrm{A}, \mathrm{B}, \mathrm{C}, \mathrm{G}$ & $\mathrm{A}, \mathrm{B}, \mathrm{C}, \mathrm{K}$ \\
\hline $\begin{array}{l}\text { Partidos com votação acumulada }>=80 \% \\
\text { na eleição para deputado }\end{array}$ & A, B & A, B & A, B \\
\hline $\begin{array}{l}\text { Partidos com votação acumulada }>=80 \% \text { na } \\
\text { eleição para deputado (votação nacional) }\end{array}$ & & A, B & \\
\hline
\end{tabular}

Elaboração própria do autor. 
Conforme apresentado no quadro, apesar de existirem três partidos disputando a presidência, apenas os partidos A e B, que concentram mais de $80 \%$ dos votos, são competitivos, sendo A o partido com mais apoio dos eleitores. (Por convenção, em todas as linhas que indicam os partidos mais votados, foram apresentados os partidos por ordem decrescente de votação da esquerda para a direita.) Nas eleições para deputado, há quatro partidos competindo nos Distritos 2 e 3, e cinco no Distrito 1. Entretanto, dada a preponderância dos partidos A e B tanto nacionalmente quanto no nível distrital na eleição presidencial, esses dois partidos experimentam crescimento nas eleições para deputado federal, ao passo que os partidos regionais, que não têm candidato, veem seu apoio eleitoral minguar. Como resultado, a eleição presidencial reduz o número de partidos em cada distrito, ao mesmo tempo que nacionaliza as eleições, fazendo com que os partidos mais competitivos em cada distrito sejam os mesmos, ou seja, a associação entre os pleitos para o Executivo e o Legislativo amplia os incentivos para a coordenação interdistrital (linkage) (Cox, 1999).

Efeito rabo de casaca presidencial e coordenação eleitoral na presença de coligações e eleições subnacionais

No exemplo apresentado no Quadro 1, conforme ficará evidente ao leitor atento, os partidos não formam coligações, concorrendo sempre de forma isolada, tanto na eleição presidencial quanto na eleição para deputado federal. Dado que a formação de coligações nas eleições para o Executivo é corriqueira em países presidencialistas multipartidários (Kellam, 2015b; West e Spoon, 2017; Freudenreich, 2016), os efeitos de coordenação eleitoral mostrados no quadro contam apenas parte da história.

Em uma análise do efeito rabo de casaca no Chile e no Brasil, Borges e Turgeon (2019) demonstram que a votação dos candidatos a presidente beneficia não apenas seus colegas de partido na eleição legislativa mas também os partidos coligados. A explicação para a existência de um efeito rabo de casaca difuso se relaciona à dinâmica de formação de coalizões pré-eleitorais na corrida presidencial. Ao decidir apoiar um candidato à presidência de outro partido, os partidos coligados abrem mão da possibilidade de controlar a presidência, bem como da oportunidade de se beneficiar da exposição na mídia de um candidato presidencial próprio. A decisão de entrar em uma coligação também pode resultar na perda de credibilidade e de apoio eleitoral se a 
coligação for percebida como inadequada, por exemplo, em razão de divergências programáticas entre os parceiros da coalizão pré-eleitoral (West e Spoon, 2017; Freudenreich, 2016).

Para Borges e Turgeon (2019), os partidos líderes da coligação presidencial entendem que a decisão dos demais partidos de entrar na coligação envolve custos e, por isso, procuram compensá-los fazendo concessões em outras disputas. Essas concessões envolvem o apoio aos membros da coalizão pré-eleitoral em eleições simultâneas, a exemplo das disputas congressuais e das eleições subnacionais. A coordenação intracoligação também pode envolver a retirada ou a redução no número de candidaturas do partido que encabeça a chapa presidencial em alguns distritos como forma de favorecer um ou mais aliados. Em outras palavras, o partido que lidera a coligação não pode se dar ao luxo de alienar os partidos coligados montando uma estratégia eleitoral com o intuito de "roubar" votos desses últimos. Pelo contrário, para manter a coligação unida, o candidato presidencial precisa fazer campanha não apenas em favor de seus copartidários mas também em favor dos aliados. Dessa forma, as legendas coligadas podem se beneficiar da associação ao candidato na hipótese de este obter bom desempenho na disputa à presidência (Borges e Turgeon, 2019). Em síntese, na presença de coligações eleitorais, os ganhos esperados da coordenação eleitoral horizontal entre as disputas para o Executivo e o Legislativo devem ser menores para o partido do candidato à presidência. Isto é, a necessidade de compensar os aliados impede que os copartidários do cabeça de chapa aumentem sua capacidade de lançar candidaturas ao Legislativo da mesma forma que fariam na ausência de uma coligação.

No caso brasileiro, a dinâmica de coordenação eleitoral se torna substancialmente mais complexa em virtude das influências do federalismo e das instituições subnacionais sobre a formação do sistema partidário. Em especial, quando as eleições para o Executivo subnacional ocorrem de forma concomitante com as eleições para o Legislativo nacional e o governador ou as lideranças partidárias estaduais influenciam de modo significativo no recrutamento de candidatos, na formação de listas partidárias e no financiamento das campanhas, abre-se espaço para a ocorrência de um efeito rabo de casaca governatorial (Jones, 1997; Samuels, 2003; Leiras, 2006; Magar, 2012; Soares, 2013). 
Cabe notar ainda que o Brasil utiliza um sistema bastante peculiar de distribuição de cadeiras dentro das coligações formadas nas disputas proporcionais, o qual favorece os pequenos partidos. Na prática, esse sistema permite que os partidos pequenos se comportem de modo estratégico, apresentando um pequeno número de candidatos com elevada votação nominal para aumentar as chances de figurar no topo da lista e ganhar cadeira, não obstante sua pequena contribuição à votação total da coligação (Calvo et al., 2015). Assim, a formação de coligações proporcionais é um dos mecanismos por meio dos quais os cabeças de chapa nos pleitos para o Executivo recompensam os partidos aliados.

É ponto pacífico na literatura sobre o Brasil que as regras eleitorais reforçam a influência dos governadores sobre o processo político-eleitoral, uma vez que muitas decisões de relevo - a exemplo das convenções partidárias para selecionar candidatos para todos os postos nacionais de relevo, com exceção da presidência - são tomadas no plano estadual (Abrucio, 1998; Lavareda, 1999; Samuels, 2003). A legislação eleitoral garante aos diretórios estaduais dos partidos substancial autonomia para tomar decisões sobre alianças partidárias. Não há, na legislação, nenhuma regra que induza a vinculação entre alianças formadas na disputa presidencial e nas disputas para governador ${ }^{2}$. Ademais, de acordo com a Lei das Eleições (Lei n ${ }^{\circ}$ 9.504, de 30 de setembro de 1997), as coligações formadas na eleição para deputado federal no distrito não podem ser incongruentes com as coligações formadas na eleição para governador ${ }^{3}$.

A rigor, a coordenação entre as eleições de presidente e de deputado federal ocorre em dois estágios. Primeiro, os partidos aliados na eleição presidencial precisam decidir se vão reproduzir ou não a mesma aliança nas eleições estaduais e quais partidos vão liderar a coligação em cada um dos distritos. Se a coordenação for efetiva, os cabeças de chapa vão abrir mão de lançar candidato em alguns estados, apoiando a candidatura a governador de um partido coligado. Em outros estados, o partido aliado vai compensar o apoio recebido retirando uma eventual candidatura para apoiar o cabeça de chapa ou outro partido da coligação (Cortez, 2009). No segundo estágio da coordenação entre os pleitos de presidente e deputado, são formadas as coligações proporcionais, seguindo em boa medida as alianças formadas na disputa a governador. A coordenação entre diferentes disputas (governador, presidente e eleições legislativas) tem levado a um crescente a especia- 
lização no interior do sistema partidário: alguns (poucos) partidos se especializam nas disputas para Executivo nacional e governadorias, ao passo que os restantes procuram garantir sua presença nos vários distritos firmando coligações nas disputas majoritárias e proporcionais com os partidos líderes (Limongi e Vasselai, 2016).

O Quadro 2 exemplifica esse processo de coordenação em dois estágios. O cenário é similar ao apresentado no Quadro 1: três candidatos disputam a eleição presidencial, sendo uma chapa isolada (partido $\mathrm{M})$ e duas coligações (A-C-K e B-G). A diferença-chave entre os exemplos do Quadro 2 e os do quadro anterior diz respeito à realização de eleições para governador simultaneamente às disputas para presidente e deputado federal. Com o objetivo de facilitar a leitura do quadro, são apresentadas apenas as coligações competitivas nas disputas majoritárias ${ }^{4}$. Relembrando: na coluna de votação acumulada, os partidos são apresentados por ordem decrescente de votação, da esquerda para a direita.

Quadro 2

Coordenação Eleitoral na Presença de Eleições para Presidente, Governador e Deputado Federal Coincidentes, com Coligações Formadas em Todos os Pleitos

\begin{tabular}{|c|c|c|c|}
\hline & Distrito 1 & Distrito 2 & Distrito 3 \\
\hline $\begin{array}{l}\text { Maiores partidos/coligações na corrida } \\
\text { presidencial no distrito (vt > 10\%) }\end{array}$ & A-C-K, B-G & A-C-K, B-G & A-C-K, B-G \\
\hline $\begin{array}{l}\text { Partidos/coligações com votação } \\
\text { acumulada >=80\% na eleição para } \\
\text { governador }\end{array}$ & M, D-G-B & A-M-C-K, B-G & K-A-C, G-B \\
\hline $\begin{array}{l}\text { Listas partidárias competindo na } \\
\text { eleição para deputado federal }\end{array}$ & $\begin{array}{l}\text { M, A-C-K, } \\
\text { D-G-B, H-I }\end{array}$ & A-M-C-K, B-G & K-A-C, G-B, H \\
\hline $\begin{array}{l}\text { Partidos/coligações com votação } \\
\text { acumulada >=80\% na eleição para } \\
\text { deputado }\end{array}$ & $\mathrm{M}, \mathrm{D}, \mathrm{G}, \mathrm{B}, \mathrm{A}$ & $\mathrm{A}, \mathrm{B}, \mathrm{G}, \mathrm{M}, \mathrm{C}, \mathrm{K}$ & $\mathrm{K}, \mathrm{G}, \mathrm{C}, \mathrm{A}, \mathrm{B}$ \\
\hline $\begin{array}{l}\text { Partidos com votação acumulada } \\
\text { >= } 80 \% \text { na eleição para deputado } \\
\text { (votação nacional) }\end{array}$ & & $\mathrm{A}, \mathrm{M}, \mathrm{C}, \mathrm{B}, \mathrm{K}, \mathrm{G}, \mathrm{D}$ & \\
\hline
\end{tabular}

Elaboração própria do autor. 
Como se vê no quadro, os partidos que lideram as coligações presidenciais estão presentes na eleição para governador com candidatos próprios apenas no Distrito 2. No Distrito 1, a coligação liderada por $\mathrm{B}$ decide apoiar o candidato de um partido ausente da disputa presidencial (D), enquanto a coligação A-C-K permanece fora da disputa. Como resultado, as coligações formadas na disputa para deputado federal são bastante distintas daquelas firmadas no pleito presidencial. Além disso, apesar de o partido $\mathrm{D}$ não estar presente na disputa presidencial, enquanto $M$ não tem candidato competitivo, ambos se beneficiam do efeito rabo de casaca governatorial e conseguem as maiores votações no distrito na eleição para a Câmara dos Deputados. Por suposto, nesse distrito os eleitores votam nos partidos que são competitivos nacionalmente na eleição para presidente e nos partidos que são competitivos em seu Estado na disputa para governador, dividindo seus votos nas duas disputas (por exemplo, alguns eleitores votam na coligação A-C-K para presidente e no partido $\mathrm{M}$ para governador).

No Distrito 3, como compensação pelo apoio recebido na eleição presidencial, os partidos A e B abrem mão de lançar candidatos a governador, apoiando partidos da coligação nacional ( $\mathrm{K}$ e $\mathrm{G}$ respectivamente). Nesse Estado, há congruência entre as coligações formadas nos planos nacional e estadual. Ainda assim, os aliados dos partidos A e B que lideram as coligações estaduais se beneficiam de forma decisiva do efeito rabo de casaca governatorial e acabam obtendo as maiores votações na disputa à Câmara Federal. $\mathrm{O}$ que se pretende demonstrar com esse exemplo é que os partidos membros da coligação presidencial podem obter tanto ganhos eleitorais diretos no pleito proporcional simultâneo, por meio de um efeito rabo de casaca presidencial difuso, quanto indiretos, pelo apoio dos partidos líderes das coligações nacionais nos pleitos para governador. Para todos os efeitos, a coordenação eleitoral multinível no interior das coligações lideradas por A e B resulta na redução da oferta de candidaturas no Distrito 3, além de agregar valiosos recursos às campanhas dos candidatos a governador dos partidos $\mathrm{K} \mathrm{e} \mathrm{G}$, incluindo tempo de televisão, apoio financeiro e logístico, entre outros. Por outro lado, A e B perdem a chance de se beneficiar diretamente do efeito rabo de casaca governatorial e de estabelecer um vínculo mais direto e de caráter propriamente partidário entre as campanhas dos candidatos a presidente e governador. 
No Distrito 2, tanto A quanto B lançam candidatos próprios a governador. As coligações estaduais são praticamente idênticas à coligação nacional, sendo a única exceção a presença do partido M na coligação liderada por A. Em tal contexto, A e B podem, ao menos teoricamente, beneficiar-se de uma "sinergia" maior entre as campanhas eleitorais de seus candidatos nos pleitos nacional e estadual. Uma integração maior entre as eleições para governador e presidente deve, por sua vez, favorecer o voto casado, levando a uma associação mais forte entre os dois pleitos majoritários e à disputa proporcional. Nesse sentido, mesmo pressupondo que os partidos coligados também se beneficiam do bom desempenho dos candidatos a presidente e a governador de $\mathrm{A}$ e B, pode-se inferir que essas duas legendas tendem a obter as maiores votações na disputa à Câmara dos Deputados. Ou seja, acredita-se que o desempenho de $\mathrm{A}$ e $\mathrm{B}$ tende a ser melhor quando ambos os partidos disputam a eleição de governador com candidato próprio do que nos casos em que concorrem apoiando outras legendas.

Cabe ressaltar, porém, que os cenários apresentados na Tabela 1 são apenas e tão somente uma simplificação da realidade. Em particular, a quase verticalização de coligações dos Distritos 2 e 3 não é regra nas eleições brasileiras. Além disso, nem todos os partidos têm os mesmos incentivos para perseguir estratégias de integração entre as eleições nacionais e estaduais (Carreirão, 2014; Borges, 2015; Melo, 2015; Borges, Albala e Burtnik, 2017). Tendo em vista essas ressalvas, pode-se inferir que a importância da estrutura da competição partidária estadual para os resultados da disputa à Câmara dos Deputados é ainda maior do que o suposto pelas eleições hipotéticas apresentadas na tabela.

Em síntese, a complexidade da coordenação eleitoral na presença de coligações e eleições simultâneas para governador e deputado federal tende a desfavorecer a vinculação das escolhas dos eleitores nas corridas eleitorais à Câmara e à presidência. Em particular, as amplas coligações multipartidárias formadas pelos cabeças de chapa na disputa presidencial lhes exigem sacrificar, ao menos em parte, suas ambições nas disputas para governador. Isto é, em troca do apoio na eleição presidencial, os partidos coligados vão demandar, quase sempre, apoio a seus candidatos a governador em alguns estados. A mesma lógica deve se reproduzir também nas disputas proporcionais, uma vez que o partido do candidato presidencial deve reduzir suas pretensões eleitorais, lançando número de candidatos menor do que o faria na ausência de uma aliança eleitoral. As compensações 
feitas aos aliados, por sua vez, impulsionam o desempenho destes nas disputas proporcionais, ao mesmo tempo que reduzem os ganhos eleitorais dos cabeças de chapa.

Esses mecanismos, em conjunto, devem resultar na neutralização do efeito redutor hipotético da disputa presidencial sobre as eleições para a Câmara dos Deputados. De fato, a fragmentação partidária no sistema político exemplificado no Quadro 1 é muito menor do que a fragmentação resultante da coordenação eleitoral exemplificada na Tabela 1, muito embora, em ambos os casos, existam apenas dois candidatos à presidência eleitoralmente viáveis.

Com base nessa discussão, podem-se apresentar duas hipóteses a serem testadas: H1: a formação de coligações na disputa presidencial produz ganhos eleitorais relevantes para os partidos que apoiam o cabeça de chapa nas disputas simultâneas para deputado federal. $\mathrm{Ou}$ seja, o efeito rabo de casaca presidencial é difuso, beneficiando não apenas os copartidários dos candidatos à presidência mas também os partidos aliados. H2: para viabilizar a formação de coligações competitivas, os partidos com candidato próprio na disputa presidencial precisam compensar os aliados por meio de apoios a seus candidatos a governador em alguns distritos, o que, por sua vez, reduz os ganhos esperados do efeito rabo de casaca presidencial. Mais especificamente, quanto maior a frequência com que o partido se faz presente na disputa para governador apoiando outras legendas, tanto menor o crescimento eleitoral decorrente de sua participação na disputa presidencial com candidato próprio.

\section{ANÁLISE EMPÍRICA}

Para teste dessas duas hipóteses, neste artigo, desenvolve-se uma série de modelos estatísticos a fim de estimar a votação nacional dos partidos em todas as disputas para a Câmara dos Deputados entre 1994 e 2014 como função das estratégias de entrada nas disputas para governador e presidente. A base de dados inclui todas as legendas que obtiveram votação igual ou superior a $1 \%$ do total nacional de votos válidos em pelo menos duas eleições para deputado federal ou que lançaram candidato à Presidência da República com votação nacional igual ou superior a 3\% do total em pelo menos uma ocasião. Obteve-se, dessa forma, um total de 87 observações válidas para 16 
partidos políticos. A Tabela 1 a seguir lista os partidos presentes na base e o respectivo número de observações.

Tabela 1

Partidos Presentes na Base de Dados e Total de Observações

\begin{tabular}{lc}
\hline Partido & Observações \\
\hline PCdoB - Partido Comunista do Brasil & 6 \\
PDT - Partido Democrático Trabalhista & 6 \\
DEM - Democratas & 6 \\
PR - Partido da República & 6 \\
PMDB - Partido do Movimento Democrático Brasileiro & 6 \\
PP - Partido Progressista & 6 \\
PPS - Partido Popular Socialista & 6 \\
PRB - Partido Republicano Brasileiro & 2 \\
Prona - Partido de Reedificação da Ordem Nacional & 4 \\
PSB - Partido Socialista Brasileiro & 6 \\
PSC - Partido Social Cristão & 6 \\
PSDB - Partido da Social Democracia Brasileira & 6 \\
PSOL - Partido Socialismo e Liberdade & 3 \\
PT - Partido dos Trabalhadores & 6 \\
PTB - Partido Trabalhista Brasileiro & 6 \\
PV - Partido Verde & 6 \\
\hline Total & 87 \\
\hline Elaboração própria do autor. & \\
&
\end{tabular}

Antes de apresentar as variáveis e os resultados dos modelos, vejamos alguns dados descritivos. O Gráfico 1 mostra a evolução da fragmentação eleitoral nas eleições presidenciais e para deputado federal desde 1945. As linhas indicam o número efetivo de candidatos presidenciais (candpres) e o número efetivo de partidos eleitorais (nepe) competindo por cadeiras na Câmara dos Deputados na eleição mais próxima à eleição presidencial. 
Gráfico 1

Número Efetivo de Candidatos à Presidência x Número Efetivo de Partidos Eleitorais (Câmara dos Deputados), 1945-2014

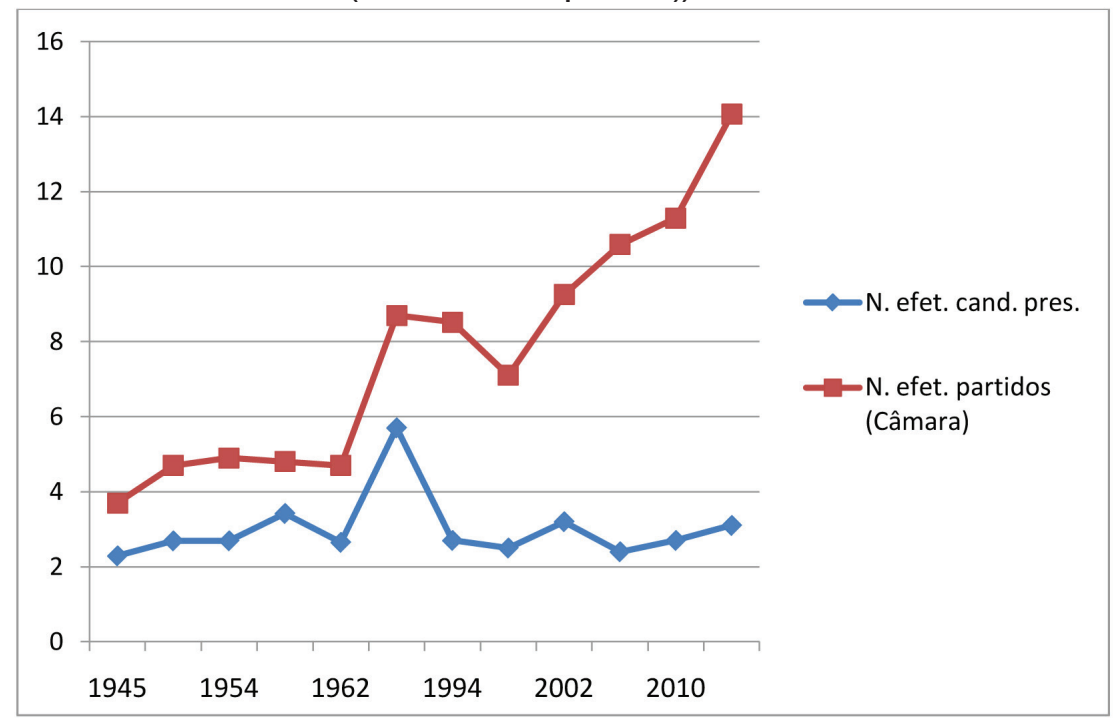

Fonte: TSE - Repositório de Dados Eleitorais; Nicolau (2004).

Como se vê, o número efetivo de candidatos na corrida presidencial variou quase sempre entre dois e três para todas as eleições democráticas realizadas entre 1945 e 2014. Em uma única ocasião (1989), o número efetivo de candidatos foi superior a quatro. Contudo, apesar de a fragmentação na disputa presidencial variar pouco no tempo, o número efetivo de partidos competindo nas eleições para a Câmara dos Deputados aumentou sistematicamente no período pós-1998. Portanto, o aumento da fragmentação não parece ser resultado da coordenação eleitoral na disputa presidencial.

O Gráfico 2 a seguir mostra o desempenho dos dois principais partidos na disputa à presidência - PT e PSDB - nas eleições para o Executivo nacional e para a Câmara dos Deputados no período entre 1990 e 2014. A votação das duas legendas em cada um dos pleitos foi somada para cada ano eleitoral. 
Gráfico 2

Votação Acumulada do PT e do PSDB nas Eleições para Presidente e Deputado Federal, 1990-2014

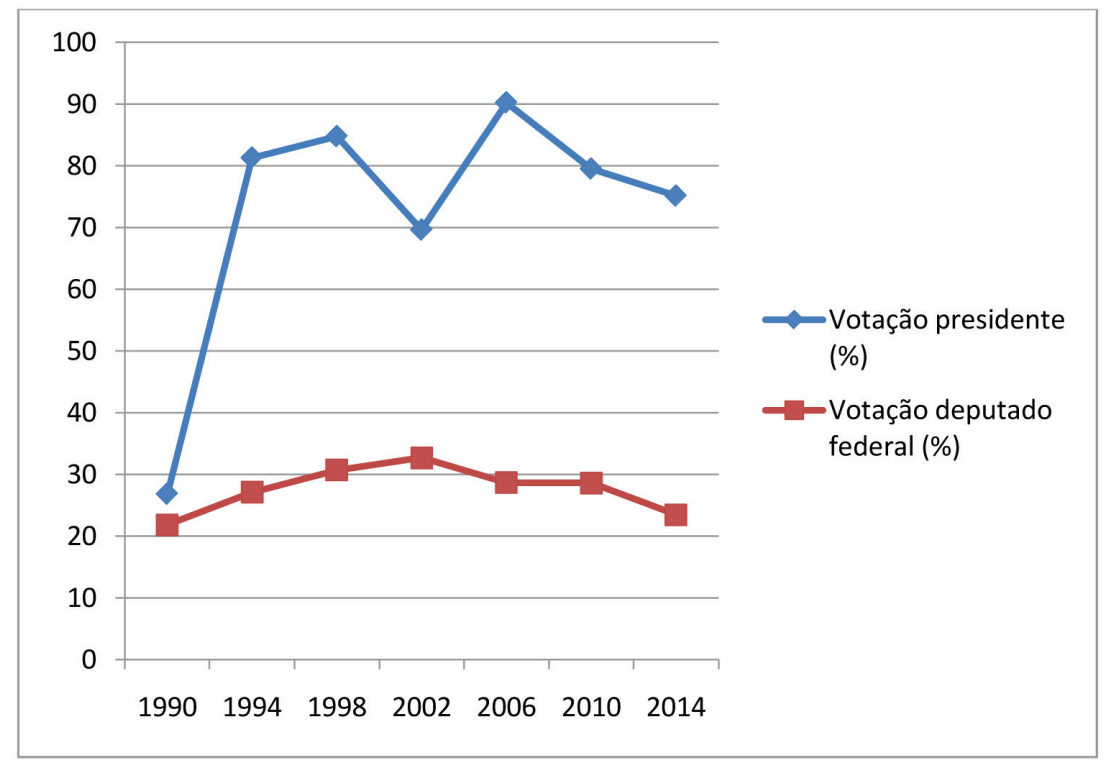

Fonte: TSE - Repositório de Dados Eleitorais.

O gráfico mostra que a concentração de votos nos candidatos presidenciais do PT e do PSDB oscilou entre 70\% e 90\% do total de votos válidos entre 1994 e 2014. No entanto, apesar da consolidação do sistema partidário presidencial em torno desses dois partidos, o percentual de votos obtidos pelo PT e pelo PSDB na eleição para deputado federal não se ampliou significativamente no período. De fato, no último ano da série (2014), o desempenho dos dois partidos foi bastante similar ao registrado em 1990: o PSDB obteve 10,2\% dos votos (contra 11,6\% em 1990), e o PT obteve participação de 13,2\% no total nacional de votos válidos (contra 10,2\% em 1990).

Quando se analisa o desempenho dos partidos que figuravam entre os quatro maiores em 1990 (exclusive PT e PSDB), é possível observar que sofreram perdas eleitorais expressivas ao longo do período. A soma das votações do PMDB, do PFL/DEM, do PDT e do PDS/PPB/ PP caiu de 65,1\% do total em 1990 para apenas 26\% em 2014. Para Melo (2006), a decadência eleitoral desses quatro partidos seria reflexo de sua incapacidade de concorrer com o PT e o PSDB na eleição presidencial. Contudo, para que essa análise fosse congruente com a literatura sobre efeito rabo de casaca, seria necessário observar uma 
massiva transferência de votos das grandes legendas para o PT e o PSDB ao longo do tempo, transferência que, conforme resta evidenciado pelo Gráfico 2, não ocorreu.

Se, por um lado, o desempenho eleitoral dos principais partidos presidenciais nas eleições para a Câmara Federal foi bastante modesto e as grandes legendas que não figuraram entre os principais competidores presidenciais sofreram perdas eleitorais expressivas, por outro os pequenos partidos obtiveram crescimento vertiginoso no período entre 1990 e 2014. O Gráfico 3 a seguir mostra a evolução da votação agregada de todos os partidos presentes na base de dados que obtiveram votações inferiores a 3\% dos votos válidos em 1990 (PCdoB, PV, PPS, PSB e PSC).

Gráfico 3

Votação dos Pequenos Partidos (Referência=1990) nas Eleições para Deputado Federal, 1990-2014

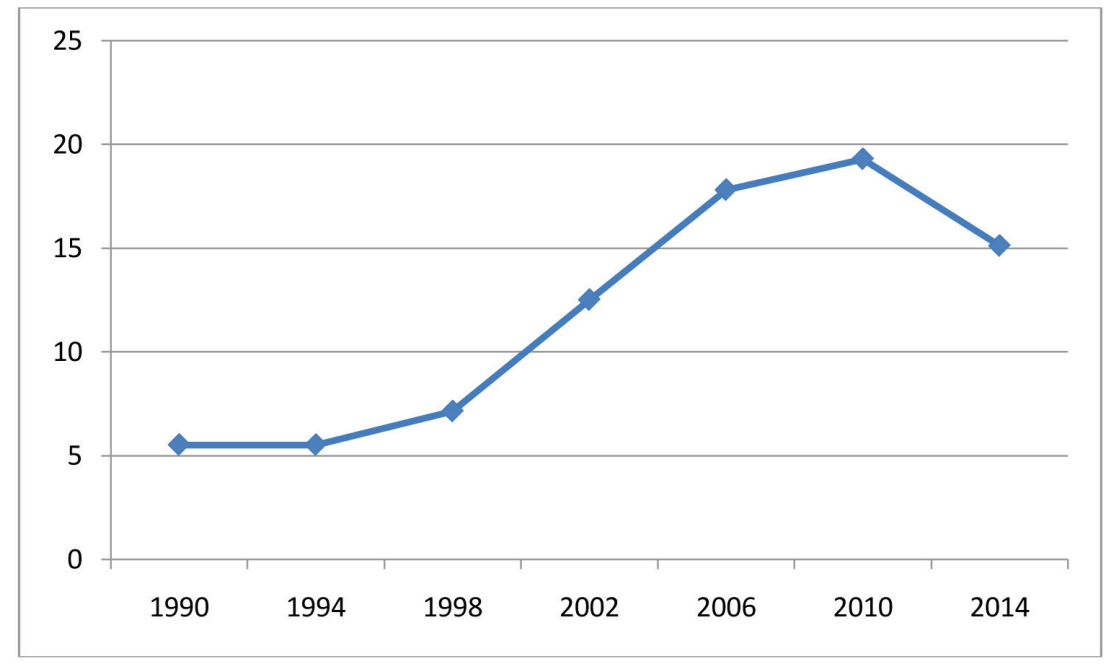

Fonte: TSE - Repositório de Dados Eleitorais.

O gráfico mostra que a soma da votação das pequenas legendas teve crescimento exponencial no período, passando de 5,5\% do total para $15 \%$ em 2014. Vale ressaltar que o gráfico inclui apenas os partidos que já existiam em 1990 (PCdoB, PV, PPS, PSB e PSC), deixando de lado as pequenas legendas que foram criadas ao longo das décadas de 2000 e 2010, e que também respondem por parcela expressiva da fragmentação registrada no último ano da série ${ }^{5}$. 
A seguir, são apresentados os resultados dos modelos estatísticos que têm como variável dependente o total nacional de votos válidos do partido $i$ no ano $t$ na eleição para a Câmara dos Deputados. Para a estimação do efeito rabo de casaca, os modelos incluem uma variável dummy que assume valor 1 se o partido lançou candidato próprio à presidência (candpres) e 0 nos demais casos, e uma medida da votação nacional do partido ou coligação na disputa presidencial como percentual do total de votos válidos (vtpres). Com o intuito de separar os efeitos da participação na eleição presidencial para os partidos com candidato próprio e os integrantes de coligações, foi adicionado aos modelos um termo interativo entre candpres e vtpres. Com a inclusão da interação, o efeito da variável de votação para presidente é o efeito estimado para os partidos presentes na eleição presidencial como membros de coligação (isto é, casos em que candpres $=0$ ). A expectativa dada pela primeira hipótese é que o efeito da votação nacional para presidente seja positivo e significativo estatisticamente ${ }^{6}$.

A fim de mensurar as estratégias de entrada dos partidos nas eleições para governador, foram criadas duas medidas que consideram: (a) o tipo de entrada na disputa (se com candidato próprio ou como membro de coligação); (b) o peso eleitoral de cada um dos estados em que o partido esteve presente na disputa para o Executivo estadual. A ponderação pelo peso eleitoral dos estados é necessária, dado que o impacto da participação na eleição para governador sobre a votação nacional para deputado depende do tamanho do eleitorado do distrito. Ou seja, ter candidatos a governador em três estados grandes, como São Paulo, Rio de Janeiro e Minas Gerais, tende a impactar mais fortemente a votação no pleito nacional proporcional do que ter candidatos a governador em um grande número de estados pequenos. O indicador de presença nas eleições para governador com candidato próprio (candgov) foi estimado pela fórmula a seguir:

\section{(1) $\sum E_{i} \times P_{i}$}

$E_{i}$ indica se o partido $j$ apresentou candidato a governador no Estado k. No primeiro caso, $E_{i}$ assume valor 1; em todos os demais casos, valor 0 . A participação do partido na disputa para governador é, em seguida, ponderada por $P_{i^{\prime}}$ que indica a proporção de votos válidos depositados na eleição realizada em cada Estado k em relação ao total nacional de votos. $\mathrm{O}$ indicador resultante pode variar de 0 (situa- 
ção em que o partido esteve ausente de todos os pleitos para governador) a 1 (situação em que o partido lançou candidato em todos os 27 estados). Para cálculo da participação dos partidos nas eleições para governador como membros de coligações (coligov), utilizou-se a mesma fórmula, com a única diferença de que o indicador $E_{i}$ foi substituído por $C_{i}$, medida que assume valor 1 para todos os casos em que o partido esteve presente na eleição para governador como membro de uma coligação.

Uma terceira medida considera de forma conjunta o peso eleitoral dos distritos e o desempenho dos partidos na eleição para governador. $\mathrm{O}$ índice de votação para governador ponderado foi calculado com base na seguinte fórmula:

(2) $\sum V_{i} x P_{i}$

$V_{i}$ indica a votação do partido na eleição para governador no Estado i, e $P_{i^{\prime}}$ assim como na fórmula anterior, mede o peso eleitoral do Estado considerando sua participação no total nacional de votos válidos. Matematicamente, esse indicador é idêntico ao total nacional da votação do partido nas eleições para governador. $\mathrm{O}$ indicador de votação para governador ponderado (vtgov) foi incluído na primeira série de modelos para controlar um possível efeito rabo de casaca governatorial. Quanto maior o índice obtido por determinado partido, melhor deve ser o desempenho na disputa proporcional.

Todos os modelos incluem um controle para a participação do partido no gabinete ministerial do presidente (coalizão). Hipoteticamente, é de se esperar que partidos da coalizão governativa tenham uma vantagem competitiva em relação aos partidos de oposição, especialmente tendo em vista a predominância do Poder Executivo no processo de produção de políticas públicas no presidencialismo brasileiro. Partidos de situação contam com acesso privilegiado aos recursos controlados pelo Executivo, incluindo a capacidade de alocar verbas, implementar políticas públicas e distribuir cargos (Meneguello, 1998; Pereira e Rennó, 2007; Inácio, 2011). A expectativa teórica é que a participação na coalizão de governo tenha um efeito positivo sobre a votação do partido, tudo o mais mantido constante.

A variável coalizão assume valor 1 se o partido ocupou ministérios durante pelo menos 50\% do mandato presidencial encerrado no ano da 
eleição t ou se esteve presente no gabinete no ano da eleição. Adotou-se o limite de 50\%, tendo em vista os casos em que o partido abandonou o gabinete nos primeiros anos do mandato, passando para a oposição. Parte-se do princípio de que o efeito da participação na coalizão tende a ser mais relevante para os partidos que permaneceram no governo durante a maior parte do mandato ou para partidos que, pelo menos, estiveram à frente de ministérios no ano da eleição.

Durante a realização dos testes estatísticos preliminares, constatou-se que as medidas de participação na coalizão governamental e de votação dos partidos coligados (efeito estimado para vtpres na presença do termo interativo) se encontram diretamente associadas. Isso se deve ao fato de que as coligações formadas pelos candidatos governistas à presidência ao longo de todo período incluíram pelo menos parte das coalizões de governo. Em alguns casos, a congruência entre a coalizão e a coligação foi praticamente total, como ocorreu nas campanhas à reeleição de Fernando Henrique Cardoso (1998) e Dilma Roussef (2014). Uma vez que os mesmos partidos costumam participar da coalizão e da aliança eleitoral, parte dos efeitos estimados para a entrada em uma coligação pode, em realidade, ser resultado dos benefícios de fazer parte do governo, e não propriamente do rabo de casaca presidencial.

Com o intuito de separar os ganhos esperados de participar de coligações presidenciais competitivas e participar da coalizão de governo, fez-se a opção por rodar uma segunda especificação incluindo uma interação da medida de participação no gabinete e o voto presidencial. Nesse modelo, o coeficiente calculado para o voto na disputa presidencial indica os efeitos da votação para presidente quando candpres $=0$ e coalizão $=0$, ou seja, para partidos coligados ausentes da coalizão governamental.

Os modelos também controlam possíveis efeitos do posicionamento ideológico dos partidos sobre sua votação. É de se esperar que partidos mais próximos do centro da distribuição de preferências ideológicas consigam disputar os votos de um pool mais amplo de eleitores, sendo o oposto verdadeiro para partidos ideologicamente extremos. Para controlar as variações no potencial eleitoral dos partidos decorrente da ideologia, foi criada uma medida que considera a distância ideológica absoluta de cada partido $x$ no ano $t$ em relação à média da distribuição ideológica dos partidos presentes na Câmara dos 
Deputados na legislatura imediatamente anterior. Em razão da não linearidade dos efeitos, optou-se pela transformação logarítmica da distância. As medidas de posicionamento ideológico se baseiam em Coppedge (1998) e Pop-Eleches (2008), e foram extraídas dos dados de replicação de Kellam (2015a).

Considerando que o teste das hipóteses requer avaliar em que medida as estratégias partidárias nas disputas para a presidência e para as governadorias explicam diferenças interpartidárias na votação para a Câmara dos Deputados, o modelo de efeitos fixos não seria o mais adequado. Esse tipo de especificação controla toda a variação entre os grupos, limitando-se a estimar os determinantes da variação longitudinal (isto é, "dentro" dos clusters) na dependente. Ademais, o modelo de efeitos fixos tende a ser mais eficiente quando $\mathrm{T}>\mathrm{N}$, o que não é o caso: o número de eleições por partido é reduzido, variando entre duas e seis para um total de 16 partidos.

Optou-se por adotar um modelo MQO com dados empilhados, incluindo como controle o tamanho do partido na eleição imediatamente anterior ao início da série (1990). Foi criada uma dummy (partpeq) que assume valor 1 para os partidos que obtiveram votações inferiores a 5\% em 1990 ou que ainda não existiam naquele momento e 0 para todos os demais casos. A opção por uma dummy em vez de se utilizar a variável dependente defasada se justifica porque a adoção do modelo autorregressivo deixaria muito pouca variação a ser explicada - o $R^{2}$ do modelo bivariado tendo como variável explicativa a votação do partido na eleição anterior para a Câmara dos Deputados é de 0,88 -, o que, por sua vez, poderia levar à subestimação dos efeitos das demais independentes. Todos os modelos reportam erros-padrão robustos de Newey-West, com correção para heterodasticidade e autocorrelação dos resíduos.

Após a realização de diagnóstico dos modelos, foi constatada a existência de uma observação influente nos modelos 1 e 2 (PMDB em 1994). Optou-se pela exclusão da observação, rodando-se novamente as regressões. Vale notar que a exclusão ou a inclusão do caso não altera substancialmente a magnitude dos efeitos nem o sinal dos coeficientes estimados, impactando, porém, sobre o ajuste do modelo.

A Tabela 2 apresenta estatísticas descritivas (média e desvio-padrão) para as variáveis contínuas presentes na base de dados. 
Tabela 2

Estatísticas Descritivas (Média e Desvio-Padrão) para Variáveis Contínuas Utilizadas nos Modelos

\begin{tabular}{lcc}
\hline & Média & Desvio-Padrão \\
\hline Voto dep. & 6,23 & 5,01 \\
Voto pres. & 24,03 & 19,87 \\
Voto gov. & 6,43 & 8,44 \\
Distância & 0,68 & 0,39 \\
Índice cand. gov. & 0,33 & 0,28 \\
Índice colig. gov. & 0,55 & 0,28 \\
\hline
\end{tabular}

Elaboração própria do autor.

A Tabela 3 a seguir apresenta os resultados dos modelos 1 e 2 utilizados para testar a hipótese 1. Essa primeira série de modelos utiliza a medida de votação ponderada para governador como proxy para o efeito rabo de casaca governatorial. O Modelo 1 inclui apenas o primeiro termo interativo entre a votação na eleição presidencial e a variável binária que indica se o partido lançou ou não candidato. $\mathrm{O}$ Modelo 2 inclui um termo interativo adicional entre a medida binária de participação na coalizão e o voto para presidente.

Tabela 3

Determinantes da Votação Nacional dos Partidos na Eleição para a Câmara dos Deputados, 1994-2014: Estratégias de Entrada nas Eleições de Governador e Presidente

\begin{tabular}{lcccc}
\hline & \multicolumn{2}{c}{ Modelo 1 } & \multicolumn{2}{c}{ Modelo 2 } \\
\hline Constante & B & sd & B & sd \\
partpequeno & $* * * 4,323$ & 0,571 & $* * * 3,269$ & 0,000 \\
$\log$ (distância) & $* * *-2,972$ & 0,368 & $* * *-2,796$ & 0,000 \\
vtpres & 0,073 & 0,206 & $-0,023$ & 0,907 \\
votogov & 0,010 & 0,014 & $* * * 0,055$ & 0,007 \\
candpres & $* * * 0,333$ & 0,050 & $* * 0,323$ & 0,000 \\
coalizão & $-0,813$ & 0,491 & $-0,220$ & 0,691 \\
vtpres X candpres & $* * * 1,372$ & 0,489 & $* * * 2,954$ & 0,000 \\
vtpres X coalizão & $* * * 0,088$ & 0,031 & $* 0,058$ & 0,070 \\
\hline N & & & $* * *-0,069$ & 0,007 \\
R2 & & 86 & & 86 \\
\hline
\end{tabular}

Fonte: TSE - Repositório de Dados Eleitorais; Kellam (2015a).

${ }^{* * *} \mathrm{p}<0,01 ;{ }^{* *} \mathrm{p}<0,05 ;{ }^{*} \mathrm{p}<0,10$ 
No Modelo 1, o coeficiente para vtpres indica o impacto dessa variável quando candpres $=0$ (e, portanto, o partido não lançou candidato à presidência). Como esperado, o efeito é positivo, porém bastante fraco e não significativo. Já no Modelo 2, com a inclusão do segundo termo interativo, o coeficiente indica o efeito da votação para presidente para partidos coligados ausentes da coalizão de governo. Essa segunda especificação indica a existência de um efeito rabo de casaca difuso, independentemente da participação no gabinete presidencial.

O Gráfico 4 a seguir mostra os valores previstos para a votação para deputado federal dos partidos coligados, conforme a votação do cabeça de chapa na disputa presidencial. O gráfico à esquerda indica a votação esperada para os partidos ausentes do gabinete do presidente; o gráfico à direita, para os partidos membros da coalizão.

\section{Gráfico 4}

Valores Previstos para Votação de Deputado Federal dos Partidos Coligados, Conforme a Votação do Cabeça de Chapa (Partidos Ausentes/Presentes na Coalizão Governamental)

(1) Partidos de oposição/ausentes do gabinete

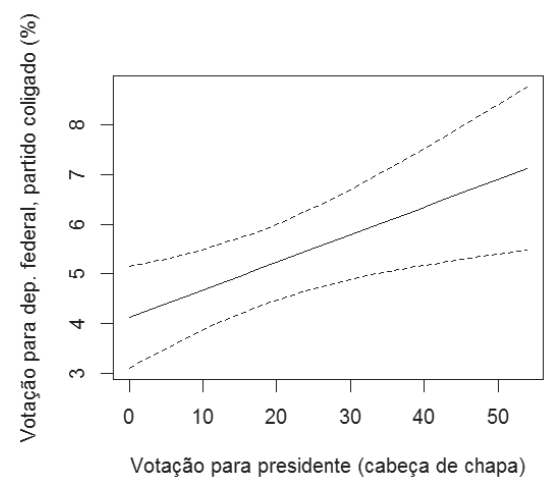

Fonte: Tabela 3, Modelo 2.
(2) Partidos membros do gabinete

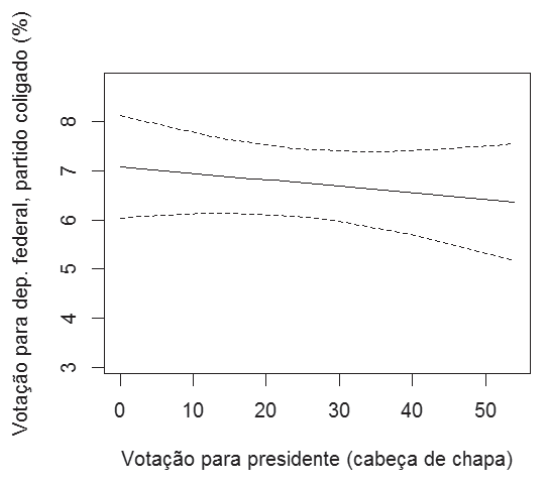

O segundo gráfico indica que os partidos da coalizão não obtêm ganhos eleitorais adicionais participando de uma coligação na disputa presidencial. De fato, a diferença entre a votação para deputado federal prevista para dois partidos da coalizão, estando um ausente da disputa presidencial e outro presente em uma coligação com votação de 30\%, é de apenas -0,29, sem significância estatística. Possivelmente, esse resultado pode estar refletindo o fato de que os partidos que fazem parte do gabinete tendem a se beneficiar dos resultados das 
políticas governamentais e da popularidade do presidente, independentemente de participarem ou não da coligação governista de modo formal, hipótese que caberia avaliar em futuros trabalhos ${ }^{7}$. De forma diversa, o primeiro gráfico mostra que há um efeito rabo de casaca difuso para os partidos ausentes da coalizão: o modelo prevê uma votação de $4,12 \%$ para um partido ausente da eleição para presidente e de $5,78 \%$ para um partido presente em uma coligação presidencial com votação de $30 \%$.

Resta saber qual é a magnitude do efeito rabo de casaca presidencial para os partidos que lançam candidato próprio, em comparação aos ganhos esperados para os partidos coligados. Para uma votação de $30 \%$ na disputa presidencial, o Modelo 1 prevê um incremento médio correspondente de $2 \%$ na votação para deputado federal dos partidos com candidato presidencial relativamente ao desempenho médio dos partidos coligados. Embora não desprezíveis, esses efeitos reforçam o argumento presente neste artigo de que o rabo de casaca presidencial difuso impossibilita a concentração dos votos nos partidos capazes de lançar candidatos presidenciais competitivos.

Tanto no primeiro quanto no segundo modelo da Tabela 3, o efeito estimado para o índice de votação nas eleições para governador é positivo e estatisticamente significativo, conforme o esperado. $\mathrm{O}$ incremento previsto na votação de um partido com votação ponderada igual à média da distribuição $(6,32)$ é de 2,08 pontos percentuais (utilizando o Modelo 1).

Também consistente com as expectativas teóricas, a variável que indica a presença do partido no gabinete do presidente em exercício (coalizão) tem um efeito forte e positivo sobre a votação na eleição para a Câmara dos Deputados. A diferença média entre as votações previstas para um partido governista e para um partido ausente da coalizão, tudo o mais mantido constante, é de aproximadamente $1,3 \%$. Essa é a diferença prevista pelo Modelo 1, que não separa os efeitos de participar da coalizão e de entrar na disputa presidencial como membro de uma coligação. O Modelo 2 estima o efeito de participar da coalizão para partidos ausentes da eleição presidencial (isto é, com votação presidencial igual a 0). Nessa segunda especificação, o ganho esperado é ainda maior, em torno de 2,9\%. Esse é um efeito bastante expressivo, considerando que a média das votações de todos os partidos e anos presentes na base de dados é de $6,4 \%$. 
A medida de distância ideológica veio com o sinal correto (negativo) apenas no Modelo 2. No entanto, em ambas as especificações, os coeficientes não obtiveram significância estatística.

O Modelo 3 a seguir utiliza uma especificação um pouco distinta dos modelos anteriores, com o intuito de mensurar o impacto médio da entrada na eleição presidencial com candidato próprio. Para tal, foi incluída uma dummy (candprescompet) que assume valor $1 \mathrm{em}$ todos os casos em que o partido entrou na eleição para presidente com candidato competitivo (isto é, com votação superior ou igual a 5\%). A rigor, não haveria razão teórica para esperar um efeito positivo da entrada na eleição para presidente com um candidato de votação marginal, o que justifica a exclusão dos casos de votação inferior a 5\% do total nacional. A outra variável de interesse é o índice de participação em coligações no pleito majoritário estadual. Interagiram-se ambas as medidas - entrada na eleição presidencial e índice de coligações. Conforme estabelecido na hipótese 2 , a expectativa é que o efeito da entrada na eleição presidencial com um candidato competitivo seja tanto mais fraco quanto maior a dependência do partido com respeito a alianças com outros partidos para se fazer presente na disputa para governador.

Teoricamente, o efeito de participar de coligações tende a ser distinto para partidos capazes de lançar candidaturas próprias em vários estados relativamente a partidos pequenos sem tal capacidade, uma vez que os últimos teriam pouco a perder entrando em coligações. De fato, na ausência de alianças com outras legendas, partidos com baixa capacidade de lançar candidatos a governador presumivelmente não teriam como se fazer presentes na disputa em muitos distritos. Dessa forma, é necessário estimar o efeito da entrada em coligações controlando a capacidade dos partidos de lançar candidaturas a governador. Como proxy, optou-se por incluir nos modelos o índice de lançamento de candidaturas ao Executivo estadual defasado.

Conforme já mencionado, os partidos com candidaturas próprias na eleição presidencial tomam decisões relativas à entrada na disputa majoritária estadual considerando a necessidade de compensar os aliados presentes na coligação nacional. Nesse sentido, é de se esperar que, quanto mais ampla a coligação formada em torno do candidato presidencial, tanto menor será o número de candidaturas 
próprias e, analogamente, maior será o número de participações na eleição para governador apoiando candidatos da coligação.

O gráfico de dispersão a seguir mostra a relação entre a dependência do partido do candidato à presidência com respeito à coligação - operacionalizada como o percentual de cadeiras do partido em relação ao total da coligação na legislatura imediatamente anterior - e $\mathrm{o}$ índice de presença em coligações no pleito para governador ${ }^{8}$. Vale notar que, nos casos em que o partido não formou coligação ou os partidos aliados não tinham nenhuma cadeira na Câmara dos Deputados, o tamanho relativo do partido assume valor 100.

\section{Gráfico 5}

Tamanho do Partido do Candidato Presidencial em Relação à Coligação (\% de Cadeiras) x Participação em Coligações (Governador)

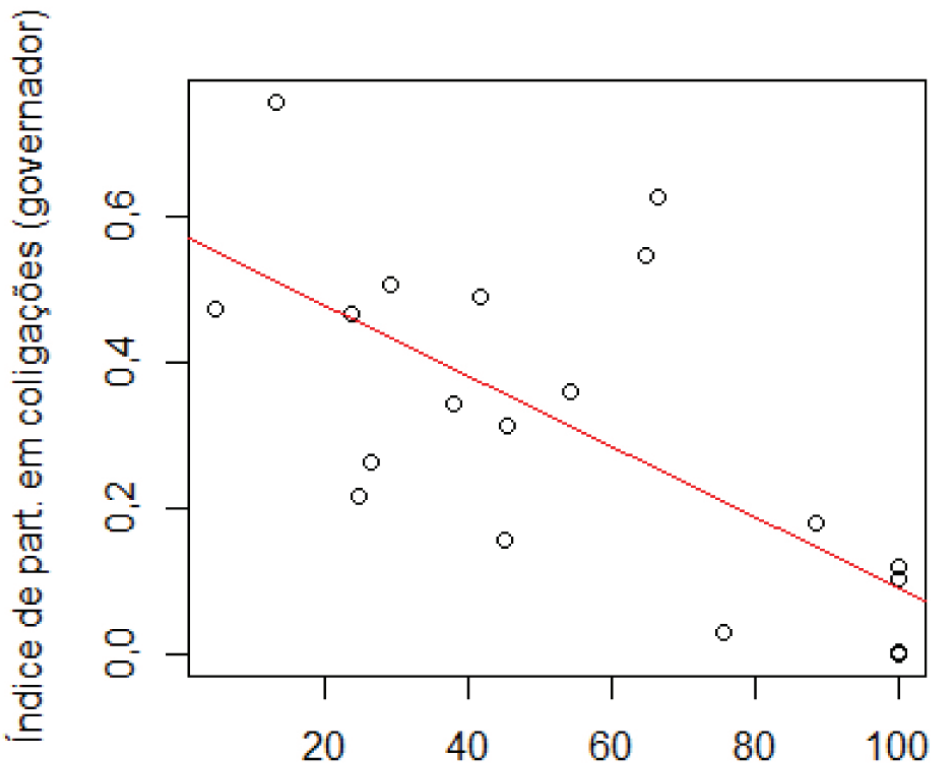

$\%$ cadeiras partido do cand. pres. / total coligação

Fonte: Câmara dos Deputados; Nicolau (1998); TSE - Repositório de Dados Eleitorais.

Como esperado, há uma relação negativa entre as duas variáveis. Isto é, quanto menor o partido do candidato presidencial em relação aos aliados, tanto maior a necessidade de compensá-los na disputa a governador e, portanto, maior a participação em coligações nesse último 
pleito. Da mesma forma, partidos que formam coligações pequenas ou concorrem de forma isolada na eleição presidencial formam coligações com pouca frequência e/ou em estados de menor importância eleitoral. A correlação entre as duas medidas é extremamente forte e negativa: $r=-0,66$. Também congruente com as expectativas teóricas, observa-se relação positiva entre o tamanho relativo do partido do candidato presidencial e o índice de lançamento de candidaturas a governador $(\mathrm{r}=0,48)$. Ou seja, quando a necessidade de compensar os aliados da coligação presidencial é baixa, os partidos privilegiam a construção de palanques próprios nos estados.

A seguir, analisamos os impactos dessas estratégias sobre a votação dos partidos na disputa à Câmara dos Deputados com base na análise dos resultados do Modelo 3 (ver Tabela 6 a seguir). Como esperado, o termo interativo entre a participação dos partidos em coligações no pleito estadual e o lançamento de candidaturas presidenciais é negativo. Isso quer dizer que os ganhos eleitorais decorrentes da entrada na eleição presidencial - coeficiente positivo para candprescompet - se reduz à medida que se amplia a presença do partido em coligações formadas nas disputas para governador.

Tabela 4

Determinantes da Votação Nacional dos Partidos na Eleição para a Câmara dos Deputados, 1994-2014 - Candidatura Própria na Disputa Presidencial x Participação em Coligações nas Eleições para Governador

\begin{tabular}{lcc}
\hline & \multicolumn{2}{c}{ Modelo 3 } \\
\cline { 2 - 3 } & B & sd \\
\hline Constante & $* * * 3,290$ & 1,396 \\
Partpequeno & $* * *-4,978$ & 0,525 \\
Log(distância) & $-0,121$ & 0,250 \\
Coalizão & $* * * 1,918$ & 0,667 \\
Candgov (lag) & $* * * 7,201$ & 1,504 \\
Coligov & 2,007 & 1,409 \\
Candprescompet & $* * 7,083$ & 1,498 \\
Candprescompet x coligov & $* *-6,771$ & 2,568 \\
\hline & & 84 \\
& & 0,692 \\
\hline Fonte: TSE - Repositório de Dados Eleitorais: Kellam (2015a)
\end{tabular}

Fonte: TSE - Repositório de Dados Eleitorais; Kellam (2015a). 
O gráfico 6, que mostra os efeitos marginais do lançamento de candidaturas presidenciais competitivas em função do índice de participação em coligações estaduais (e os respectivos intervalos de confiança nas linhas tracejadas), confirma a intuição básica obtida pelo exame dos coeficientes do modelo. $\mathrm{O}$ ganho eleitoral da entrada na disputa presidencial com candidato próprio atinge seu máximo quando a participação em coligações nas eleições para governador é nula (efeito marginal de 7,08\%). O ganho previsto se reduz em quase quatro pontos percentuais (efeito marginal de 3,2\%) quando o índice de participação em coligações assume o valor médio $(0,55)$. Para valores iguais ou superiores a 0,73 , a entrada na eleição presidencial com candidato próprio não produz efeitos estatisticamente significativos.

Gráfico 6

Efeito Marginal de Lançar Candidato à Presidência para Diferentes Níveis de Participação em Coligações nos Pleitos para Governador

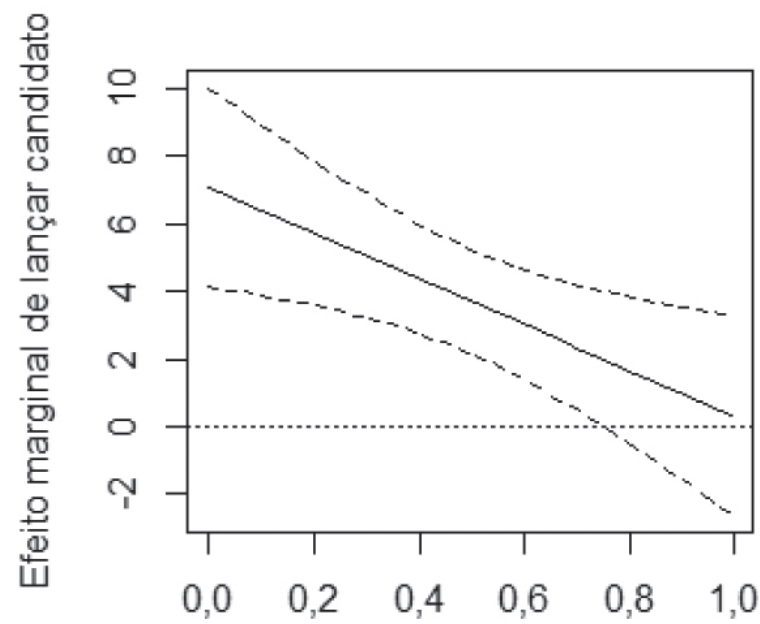

Participação em coligações (governador)

Fonte: Tabela 4, Modelo 3.

Os resultados dos modelos confirmam parcialmente a hipótese 1. Os partidos coligados se beneficiam de um efeito rabo de casaca difuso, conforme demonstrado pelo Modelo 2, porém esse efeito só se verifica para partidos ausentes da coalizão governista. Em acordo à hipótese 2, o apoio a outras legendas nas eleições para governador reduz o impacto do lançamento de um candidato presidencial competitivo 
sobre o desempenho dos partidos nas eleições simultâneas para a Câmara dos Deputados.

\section{CONCLUSÃO}

Este artigo começou com um enigma: por que as eleições presidenciais não são capazes de estruturar o sistema partidário brasileiro, reduzindo o número de partidos eleitoralmente viáveis na disputa à Câmara Federal? Os resultados da análise empírica sugerem, de forma distinta do que é suposto pelas hipóteses convencionais, que o aumento sistemático da fragmentação partidária no período recente é parcialmente endógeno à dinâmica coalizacional do presidencialismo brasileiro nas arenas eleitoral e governativa.

A barganha intracoligação adquire complexidade no caso brasileiro em virtude da interação entre as instituições federativas e eleitorais. A simultaneidade entre as eleições de governador e deputado federal, em combinação com a centralidade da arena estadual para as estratégias de lançamento de candidaturas e a formação de alianças nas disputas ao Legislativo nacional, produz um efeito rabo de casaca governatorial relativamente independente da estrutura da competição pela presidência. Por outro lado, a necessidade de compensar os aliados na disputa a governador obriga os partidos com candidato próprio à presidência a abrir mão de lançar candidatos em vários distritos, apoiando os membros da coligação nacional. Como resultado, os partidos presidenciais perdem a capacidade de integrar as campanhas de seus candidatos à presidência e às governadorias, ao mesmo tempo que abrem mão de potenciais ganhos eleitorais decorrentes do efeito rabo de casaca governatorial. Os resultados mostram também que o efeito rabo de casaca é difuso, beneficiando não apenas os partidos capazes de lançar candidatos à presidência mas também aqueles que se coligam. Entretanto, esses efeitos parecem ser de menor relevo para explicar o crescimento sistemático dos pequenos partidos, tendo em vista só se verificarem para as legendas ausentes do gabinete presidencial.

Do ponto de vista teórico, o efeito redutor sobre o número efetivo de partidos em função do pequeno número de candidatos viáveis em eleições presidenciais simultâneas tem relação direta com os ganhos esperados da organização de grandes partidos nacionais capazes de competir efetivamente pela presidência. Quando os partidos não for- 
mam coalizões pré- e pós-eleitorais, competindo de forma isolada na disputa presidencial, a capacidade de vencer esse último pleito se torna condição necessária para chegar ao governo. Em boa parte dos sistemas presidencialistas multipartidários, entretanto, a formação de coalizões pré- e pós-eleitorais torna mais difícil prever os efeitos em longo prazo do rabo de casaca presidencial, dado que partidos pequenos podem sobreviver e ganhar votos se coligando aos partidos viáveis na disputa à presidência ou formando coalizões no período pós-eleitoral.

No caso brasileiro, essa lógica é levada às últimas consequências por um sistema eleitoral que facilita enormemente a obtenção de cadeiras por partidos pequenos e pouco nacionalizados - graças às coligações proporcionais -, ao mesmo tempo que abre às legendas não competitivas a possibilidade de barganhar o apoio dos partidos líderes das coligações presidenciais em favor de seus candidatos a governador em estados-chave.

Soma-se a esses aspectos o fato de que a participação no gabinete presidencial tem grande impacto sobre o crescimento eleitoral dos partidos, como demonstrado pelos modelos estatísticos. Participar de amplas e heterogêneas coalizões pré- e pós-eleitorais garante a sobrevivência dos pequenos partidos, permitindo que estes aumentem seu poder de barganha a cada nova eleição e novo governo formado, retroalimentando a fragmentação do sistema.

De modo geral, as evidências sugerem que os principais partidos brasileiros no período 1994-2014 - PT e PSDB - representam casos extremos de "presidencialização". Conforme notam Samuels e Shugart (2010), a separação de poderes induz os partidos que se especializam na disputa à presidência a sacrificar suas ambições em outras disputas eleitorais para garantir bons resultados na eleição presidencial, concentrando seus recursos e esforços nesse último pleito.

Com a entrada em vigor da cláusula de barreira em 2018 e o fim das coligações nas eleições para a Câmara dos Deputados a partir de 2022, é de se esperar que haja uma tendência à estabilização do quadro partidário, impondo um freio à fragmentação 9 . Vale ressaltar, porém, que o relativo descolamento entre a votação dos principais candidatos à presidência e de seus partidos resulta não apenas das regras eleitorais que regem a disputa proporcional, mas da própria 
dinâmica de formação de coalizões nas arenas eleitoral e governativa. A combinação entre governos subnacionais autônomos e dinâmica partidária "estadualista", multipartidarismo e eleições simultâneas em distintos níveis de governo torna extremamente complexo e custoso o processo de formação de alianças em torno dos principais postulantes à presidência. Essas instituições atuam em conjunto no sentido de reduzir os ganhos eleitorais esperados do lançamento de candidaturas presidenciais competitivas, cenário que não deve se alterar substancialmente no futuro próximo.

(Recebido para publicação em 8 de novembro de 2017)

(Reapresentado em 30 de agosto de 2018)

(Aprovado para publicação em 12 de fevereiro de 2019) 


\section{NOTAS}

1. O número efetivo de partidos é uma medida de fragmentação que leva em conta o grau de concentração ou de dispersão dos votos (ou cadeiras) entre os partidos. A fórmula de cálculo é $1 / \sum p_{i}$, sendo $\mathrm{p}_{\mathrm{i}}$ a proporção de votos (cadeiras) do i-ésimo partido.

2. A única tentativa relevante para acabar com a autonomia dos diretórios estaduais dos partidos foi a instituição da regra da "verticalização" em 2002 e em 2006 pelo Tribunal Superior Eleitoral (TSE), que obrigava os partidos a reproduzir as alianças formadas na disputa presidencial nas eleições para governador. Em 2006, no entanto, o Congresso aprovou uma emenda constitucional que cancelou os efeitos da resolução.

3. A lei de 1997 estabelece que dois partidos pertencentes a coligações distintas na eleição para governador não podem formar coligação no pleito para a Câmara dos Deputados. A Lei $n^{\circ} 8.713 / 1993$ era ainda mais restritiva. Conforme interpretação do TSE na época, as coligações formadas nas disputas proporcionais tinham de ser sempre e necessariamente idênticas àquelas formadas na eleição para governador (Marchetti e Cortez, 2009).

4. Também se adotou, em favor da simplicidade analítica, o suposto de que as coligações proporcionais sempre coincidem com as coligações formadas na disputa majoritária estadual. Na prática, isso nem sempre ocorre, pois uma coligação hipotética composta pelos partidos A-B-C-D na eleição para governador pode se dividir em duas ou mais coligações (por exemplo, A-B e C-D) na disputa à Câmara dos Deputados.

5. É importante notar que alguns dos pequenos partidos existentes no início da década de 1990 optaram pela fusão com outras legendas. Esse é o caso do PDC (Partido Democrata Cristão), que se fundiu com o Partido Democrático Social (PDS) em 1993, criando o Partido Progressista Reformador (PPR). Uma vez que esses partidos deixaram de existir, não há como avaliar seu desempenho ao longo do tempo.

6. No caso dos partidos ausentes da eleição presidencial, a variável vtpres assume valor 0 , de modo que o efeito da votação presidencial para esses partidos é necessariamente nulo.

7. Borges e Turgeon (2019) demonstraram que os aliados ideologicamente distantes do cabeça de chapa e sem participação prévia em alianças com o candidato presidencial não se beneficiam do rabo de casaca difuso. O pequeno número de casos na base não permite testar adequadamente essa hipótese, mas vale notar que os autores não consideraram o efeito da participação nas coalizões governamentais.

8. Incluíram-se, no gráfico, apenas os partidos com candidatos presidenciais que tiveram votações iguais ou superiores a $5 \%$ dos votos válidos.

9. A proposta de emenda à Constituição foi aprovada em 21 de setembro de 2017 e prevê uma cláusula de barreira progressiva para acesso ao fundo partidário e tempo de televisão, iniciando com 1,5\% dos votos válidos e nove deputados federais eleitos em 2018, e chegando a 3\% dos votos e 15 eleitos em 2030. A emenda também prevê o fim das coligações proporcionais a partir de 2020. 


\section{REFERÊNCIAS BIBLIOGRÁFICAS}

ABRUCIO, Fernando L. (1998), Os Barões da Federação: os governadores e a redemocratização brasileira. São Paulo: Hucitec.

AMES, Barry. (2001), The Deadlock of Democracy in Brazil. Ann Harbor: The University of Michigan Press.

AMORIM NETO, Octavio. (2007), “Algumas consequências políticas de Lula: novos padrões de formação e recrutamento ministerial, controle de agenda e produção legislativa". In: J. Nicolau; T. Power (org.), Instituições representativas no Brasil: balanço e reforma. Belo Horizonte: Editora UFMG, pp. 55-73.

BORGES, André. (2015), “Nacionalização partidária e estratégias eleitorais no presidencialismo de coalizão". DADOS, v. 58, pp. 239-274.

BORGES, André; TURGEON, Mathieu. (2019), "Presidential coattails in coalitional presidentialism". Party Politics, v. 25, n. 2, pp. 191-202.

BORGES, André; ALBALA, Adrián; BURTNIK, Lucía C. (2017), “Pathways to nationalization in multilevel presidential systems: accounting for party strategies in Brazil and Argentina". Publius - The Journal of Federalism, v. 47, n. 4, pp. 648-672.

CALVO, Ernesto et al. (2015), "Why Coalitions? Party system fragmentation, small party bias, and preferential vote in Brazil". Electoral Studies, v. 39, pp. 219-229.

CARREIRÃO, Yan de Souza. (2014), “O sistema partidário brasileiro: um debate com a literatura recente". Revista Brasileira de Ciência Política, v. 14, pp. 255-275.

COPPEDGE, Michael. (1998), "The dynamic diversity of latin american party systems". Party Politics, v. 4, pp. 547-568.

CORTEZ, Rafael. (2009), Eleições majoritárias e entrada estratégica no sistema partidário-eleitoral brasileiro, Tese (Doutorado em Ciência Política), Universidade de São Paulo, Brasil.

COX, Gary. (1999), "Electoral rules and electoral coordination". Annual Review of Political Science, v. 2, pp. 145-161.

FIGUEIREDO, Argelina Cheibub; LIMONGI, Fernando. (1999), Executivo e Legislativo na Nova Ordem Constitucional. Rio de Janeiro: Editora FGV.

. (2000), "Presidential power, legislative organization, and party behavior in Brazil". Comparative Politics, v. 32, n. 2, pp. 151-170.

FREUDENREICH, Johannes. (2016), "The formation of cabinet coalitions in presidential systems". Latin American Politics and Society, v. 58, pp. 80-102.

GOLDER, Matt. (2006), "Presidential Coattails and Legislative Fragmentation". American Journal of Political Science, v. 50, n. 1, pp. 34-48.

HICKEN, Allen; STOLL, Heather. (2011), "Presidents and parties: how presidential elections shape coordination in legislative elections". Comparative Political Studies, v. 44, pp. 854-883. 
INÁCIO, Magna. (2011), "Engajamento parlamentar no Brasil”. In: T. Power; C. Zucco (orgs.), O Congresso por Ele mesmo: autopercepções da classe política brasileira. Belo Horizonte: Ed. UFMG.

JONES, Mark. (1994), "Presidential election laws and multipartism in latin america". Political Research Quarterly, vol. 61, pp. 171-184.

. (1997), "Federalism and the number of parties in argentine congressional elections". The Journal of Politics, v. 59, pp. 538-549.

KELLAM, Marisa. (2015a), "Parties for hire: how particularistic parties influence presidents' Governing Strategies". Party Politics, v. 21, pp. 515-526.

. (2015b), "Why Pre-Electoral Coalitions in Presidential Systems?". British Journal of Political Science, v. 47, pp. 391-411.

LAVAREDA, José Antônio. (1999), A democracia nas urnas: o processo partidário-eleitoral brasileiro (1945-1964). Rio de Janeiro: Revan.

LEIRAS, Marcelo. (2006), “Parties, provinces and electoral coordination: a study on the determinants of party and party system aggregation in Argentina, 1983-2005. Dissertação (Mestrado em Ciência Política), University of Notre Dame.

LIMONGI, Fernando; CORTEZ, Rafael. (2010), "As eleições de 2010 e o quadro partidário". Novos Estudos Cebrap, n. 88, pp. 21-37.

LIMONGI, Fernando; VASSELAI, Fabrício. (2016), “Coordenando candidaturas: coligações e fragmentação partidária nas eleições gerais brasileiras". Trabalho apresentado no $\mathrm{X}$ Encontro da ABCP, 30/8-2/9, Belo Horizonte, MG.

MAGAR, Eric. (2012), "Gubernatorial coattails in mexican congressional elections". The Journal of Politics, v. 74, pp. 383-399.

MAINWARING, Scott. (1999), rethinking party systems in the third wave of democratization: the case of Brazil. Stanford: Stanford University Press.

MARCHETTI, Vitor; CORTEZ, Rafael. (2009), “A judicialização da competição política: o TSE e as coligações eleitorais". Opinião Pública, v. 15, pp. 422-450.

MARTÍNEZ-GALLARDO, Cecilia. (2010), "Inside the cabinet: the influence of ministers in the policymaking process". In: C. Scartascini; E. Stein; M. Tommasi (orgs.), How democracy works: political institutions, actors, and arenas in latin american policymaking. Washington, D.C.; Cambridge, MA: Inter-American Develpment Bank; David Rockefeller Center for Latin American Studies. pp. 119-146.

. (2012), "Out of the cabinet: what drives defections from the government in presidential systems?". Comparative Political Studies, v. 45, n. 1, pp. 62-90.

MELO, Carlos Ranulfo. (2006), "Sistema partidário, presidencialismo e reforma política no Brasil”. In: G. A. D. Soares; L. Rennó (orgs.), Reforma política: lições da história recente. Rio de Janeiro: Editora FGV.

. (2015), "The 2014 Elections and the brazilian party system". Brazilian Political Science Review, v. 9, pp. 93-114. 
MENEGUELLO, Rachel. (1998), Partidos e governos no Brasil contemporâneo. São Paulo: Paz e Terra.

(1998), Dados Eleitorais do Brasil (1982-1996). Rio de Janeiro: Revan.

NICOLAU, Jairo. (2004), “Partidos na República de 1946: velhas teses, novos dados”. DADOS, v. 47, n. 1 , pp. 85-129.

PEREIRA, Carlos et al. (2016), "All the president's men and women: coalition management strategies and governing costs in a multiparty presidency". Presidential Studies Quarterly, v. 46, pp. 550-568.

PEREIRA, Carlos; RENNÓ, Lucio. (2007), “O que é que o reeleito tem? o retorno: o esboço de uma teoria da reeleição no Brasil”. Revista de Economia Política, v. 27, n. 4, pp. 664-683.

POP-ELECHES, Grigore. (2008), From economic crisis to reform: Imf programs in Latin America and Eastern Europe. Princeton: University Press.

SAMUELS, David. (2002), "Presidentialized parties: the separation of powers and party organization and behavior". Comparative Political Studies, v. 35, pp. 461-483.

. (2003), Ambition, federalism, and legislative politics in Brazil. Cambridge: Cambridge University Press.

SAMUELS, David; SHUGART, Matthew. (2010), Presidents, parties and prime ministers: how the separation of powers affects party organization and behavior. New York: Cambridge University Press.

SHUGART, Matthew. (1995), "The electoral cycle and institutional sources of divided government". American Political Science Review, v. 89, pp. 327-343.

SHUGART, Matthew; CAREY, John M. (1992), Presidents and assemblies: constitutional design and electoral dynamics. Cambridge, UK: Cambridge University Press.

SOARES, Márcia Miranda. (2013), “Influência majoritária em eleições proporcionais: os efeitos presidenciais e governatoriais sobre as eleições para a Câmara dos Deputados brasileira (1994-2010)". DADOS, v. 56, n. 2, pp. 413-437.

WEST, Karleen Jones; SPOON, Jae-Jae. (2017), “Coordination and presidential coattails: do parties' presidential entry strategies affect legislative vote share?". Party Politics, v. 23, n. 5, pp. 578-588.

ZUCCO, Cesar. (2008), “The president's 'new' constituency: Lula and the pragmatic vote in Brazil's 2006 presidential elections". Journal of Latin American Studies, v. 40, n. 1, pp. 29-49. 


\section{RESUMO}

Razões da Fragmentação: Coligações e Estratégias Partidárias na Presença de Eleições Majoritárias e Proporcionais Simultâneas

As explicações institucionalistas sobre o formato dos sistemas partidários asseveram que eleições presidenciais e congressuais coincidentes, na presença de pequeno número de candidatos presidenciais, reduz o número de partidos na disputa ao Legislativo. Não obstante a simultaneidade dos pleitos para deputado e presidente desde 1994, e a estabilização do número de candidatos presidenciais viáveis, a fragmentação partidária vem aumentando sistematicamente no Brasil. Este artigo procura entender as razões do descolamento entre a estrutura da competição pela presidência e a disputa eleitoral para a Câmara dos Deputados. $\mathrm{O}$ artigo aponta para a atuação de um efeito rabo de casaca difuso que permite aos partidos, sem candidatos viáveis à presidência, obter ganhos eleitorais participando de coligações na disputa presidencial. Para vencer a disputa presidencial, os partidos capazes de concorrer com candidato próprio formam coligações amplas, que requerem a compensação dos aliados em disputas simultâneas. A coordenação intracoligação produz perdas eleitorais para os cabeças de chapa nas eleições para deputado federal, ao mesmo tempo que impulsiona o desempenho dos partidos coligados. O artigo testa estas hipóteses por meio de uma série de modelos estatísticos que estimam os determinantes da votação nacional dos partidos em todas as disputas para Câmara dos Deputados entre 1994 e 2014.

Palavras-chave: sistema partidário; presidencialismo; eleições presidenciais; coligações

\section{ABSTRACT \\ Reasons for Fragmentation: Party Coalitions and Strategies Regarding Simultaneous Majoritarian and Proportional Elections}

Institutionalist explanations about the format of party systems assert that coincident presidential and congressional elections, in the presence of small numbers of presidential candidates, reduce the number of parties in the dispute to the legislature. Despite the system of simultaneous elections for president and deputies established in 1994 and the stabilization of the number of viable presidential candidates, party fragmentation has been systematically increasing in Brazil. This article tries to understand the reasons for the detachment between the structure of the competition for the presidency and the electoral dispute for the Chamber of Deputies. The article points to a diffuse coattail effect that allows parties without viable candidates to win electoral benefits by participating in coalitions in the presidential race. To win the presidential race, parties capable of 
competing with their own candidates form broad coalitions, which require the allies to be compensated in simultaneous disputes. Intra-collective coordination produces electoral losses for the head of the slate in the elections of federal deputies, while at the same time boosts the performance of the related parties. The article tests these hypotheses through a series of statistical models that estimate the determinants of national party voting in all disputes for the Chamber of Deputies between 1994 and 2014.

Keywords: party system; presidentialism; presidential elections; coalitions

\section{RÉSUMÉ}

Raisons de la Fragmentation: Coalitions et Stratégies de Parti en Présence d'Élections Majoritaires et Proportionnelles Simultanées

Des explications institutionnalistes sur le format des systèmes de partis affirment que des élections présidentielles et législatives coïncidentes, en présence d'un petit nombre de candidats à la présidence, réduisent le nombre de partis en lice pour le parlement. Malgré les élections simultanées à la présidence et à la députation depuis 1994 et la stabilisation du nombre de candidats viables à la présidence, la fragmentation des partis a systématiquement augmenté au Brésil. Cet article tente de comprendre les raisons du détachement entre la structure du concours pour la présidence et le différend électoral pour la Chambre des députés. L'article souligne la performance d'un effet d'entraînement (effet coattail) diffus qui permet aux partis, sans aucun candidat viable à la présidence, d'obtenir des gains électoraux en participant à des coalitions dans la course à la présidence. Pour remporter la course à la présidence, les partis capables de rivaliser avec leur propre candidat forment de vastes coalitions, qui exigent que les alliés soient indemnisés lors de conflits simultanés. La coordination intracollective produit des pertes électorales pour les têtes de liste lors des élections aux postes de député fédéral, tout en améliorant la performance des parties liées. L'article teste ces hypothèses à l'aide d'une série de modèles statistiques qui estiment les facteurs déterminants du vote des partis nationaux dans tous les différends pour la Chambre des députés entre 1994 et 2014.

Mots-clés: système de parti; présidentialisme; élections présidentielles; coalitions. 


\section{RESUMEN}

Razones de la Fragmentación: Coaliciones y Estrategias Partidarias en la Presencia de Elecciones Mayoritarias y Proporcionales Simultáneas

Las explicaciones institucionalistas sobre el formato de los sistemas partidarios aseveran que elecciones presidenciales y parlamentarias simultáneas, en la presencia de un pequeño número de candidatos presidenciales, reduce el número de partidos en la disputa al legislativo. A pesar de la simultaneidad de la contienda electoral para diputados y presidente desde 1994 y la estabilización del número de candidatos presidenciales viables, la fragmentación partidaria viene aumentando sistemáticamente en Brasil. Este artículo busca entender las razones del movimiento entre la estructura de la competencia por la presidencia y la disputa electoral para la Cámara de los Diputados. El artículo señala la acción de un efecto de arrastre difuso que permite a los partidos, sin candidatos viables a la presidencia, obtener ganancias electorales participando de coaliciones en la disputa presidencial. Para vencer la disputa presidencial, los partidos capaces de competir con un candidato propio forman coaliciones amplias, que requieren la compensación de los aliados en disputas simultáneas. La coordinación al interior de la coalición produce pérdidas electorales para los candidatos que encabezan las listas en las elecciones para diputado federal, al mismo tiempo en que impulsan el desempeño de los partidos de la coalición. El artículo prueba estas hipótesis por medio de una serie de modelos estadísticos que estiman los determinantes a la votación nacional de los partidos en todas las disputas para la Cámara de los Diputados entre 1994 y 2014.

Palabras clave: sistema partidario; presidencialismo; elecciones presidenciales; coaliciones 